Universidad de Guadalajara

Derecho Gloabal. Estudios sobre Derecho y Justicia

Año 4, núm 10, noviembre 2018- febrero 2019, pp. 51-76, ISSN: 2448-5128, e-ISSN: 2448-5136 https://doi.org/10.32870/dgedj.v0i10.195

\title{
Presunción de inocencia en materia de procedimiento administrativo sancionador. Matices y modulaciones
}

\section{Presumption of innocence in the administrative sanctions procedure. Nuances and graduations}

\author{
Arturo Heriberto Sanabria Pedraza \\ Universidad Autónoma de Querétaro, México \\ arturo.sanabria.pedraza@gmail.com
}

Recibido: 09/03/18 | Aceptado: 04/05/18

RESUMEN: Este trabajo tiene por objetivo reducir la ambigüedad y las contradicciones durante la interpretación y aplicación del derecho a la presunción de inocencia en el derecho administrativo. El estudio comienza con el desarrollo que este derecho ha tenido en la materia penal, luego se evalúa cada elemento que lo conforma y se expone uno a uno si ha de ser matizado o modulado según su compatibilidad con el derecho administrativo sancionador. Este esfuerzo pretende evitar que se hagan indebidas yuxtaposiciones interpretativas entre estas materias. El estudio concluye con la formulación de criterios que se proponen delimitar la extensión de este derecho con base en las particularidades de la materia administrativa. Las fronteras entre ambas materias serán más claras mientras mayor sea su estudio, consenso, y difusión.

PALABRAS CLAVE: Procedimiento Administrativo Sancionador, presunción de inocencia, derecho penal, derechos humanos.

ABSTRACT : The goal of this paper points out to reduce the ambiguity and the contradictions related with the presumption of innocence when it is interpreted and applied in the field of administrative sanctions procedure. We start with the developing of this right in the criminal law field. We check each presumption of innocence's element, then we determine, one by one, if we should give to them any kind of nuances or graduations according to its compatibility with the field of administrative sanctions procedure. This effort pretends to avoid improper juxtapositions among the interpretations in these fields of law. This study finishes with the proposal of different kinds of criteria to delimit the extension of the presumption of innocence based on the special features of the administrative sanctions procedure. The boundaries will be clearer as much as their studies and consensus are diffused.

KEY WORDS: Law of administrative sanctions procedure, presumption of innocence, criminal law, humans rights. 


\section{SUMARIO}

I. Introducción. II. Principio o derecho. III. Presunción de inocencia en materia penal. IV. Presunción de inocencia del derecho penal al proceso administrativo sancionador. V. Presunción de inocencia, sus matices y modulaciones. VI. Confesión ficta. VII. Operadores del derecho. VIII. Conclusiones. Bibliografía.

\section{Introducción}

El desarrollo que ha tenido esta presunción en el ámbito penal, por los efectos que se producen en esta materia, genera enormes expectativas en el derecho administrativo sancionador, sin embargo, el entusiasmo dura poco cuando se conoce que su reconocimiento en la materia administrativa nació condicionado por una serie de excepciones que la Suprema Corte de Justicia de la Nación nombró "matices y modulaciones", aun y cuando ellos no fueron identificados. Ante la incertidumbre que ello genera, este artículo hace una aproximación al fenómeno poniendo en perspectiva criterios y debates que han tenido lugar en el foro nacional como en el internacional, para así tener una idea más clara sobre lo que podemos esperar y lo que no de esta presunción legal.

El análisis parte de un enfoque conceptual y se desarrolla gradualmente a través de precedentes significativos que ilustran cómo opera este principio en la justicia administrativa sancionadora en la actualidad.

\section{Principio o derecho}

Es indispensable determinar la naturaleza jurídica de la presunción legal de inocencia porque, según se sitúe en una u otra posición, su significado y alcances serán distintos.

La presunción de inocencia en su génesis fue considerada como principio teórico del derecho, como un dogma jurídico principialista al considerar apriorísticamente a toda persona como inocente. Se trata de un principio interpretativo que se emplea para formular juicios de valor. Al respecto, la Corte Interameri- 
cana de Derechos Humanos afirma que "[e]n el ámbito penal... el principio de presunción de inocencia constituye un fundamento de las garantías judiciales." (CrIDH, 2011, p. 50).

Reconocido como principio, su contenido y alcance son indeterminados, esto es, no encuentran condiciones exactas de aplicación en oposición a las reglas. Si bien es un concepto indeterminado, es susceptible de concretarse, se caracteriza por tener una flexibilidad que le permite adaptarse a las circunstancias del caso, y permite con ello ajustar su aplicación beneficiando de la manera más -o menos- amplia a la persona.

Como principio, esta presunción se convierte en un recurso argumentativo para producir nuevas obligaciones creadas discrecionalmente por el juzgador, su debilidad está en qué, como principio, es meramente orientador hacia el Estado y hacia la administración.

Argumentando su universalidad, a la presunción de inocencia deviene en un derecho subjetivo e inherente a toda persona a ser considerada y tratada como inocente respecto de la acusación formal en su contra. A partir de esta definición, esta presunción tiene un alcance más claro, al contar con una redacción normativa oponible al Estado. En este tratamiento coinciden la Convención Americana sobre Derechos Humanos (1969, art. 8.2), la Declaración Universal de los Derechos Humanos (1948, art. 11.1), el Pacto Internacional de Derechos Civiles y Políticos (1966, art. 14.2) y la Constitución Política de los Estados Unidos Mexicanos (2018, art. 20.I.B). La coincidencia entre estos instrumentos radica en considerar a la presunción de inocencia como un derecho del inculpado durante el proceso penal.

Finalmente, otras perspectivas como la de José Nestos García Reza, identifican a esta presunción como "un estado jurídico del indiciado por el cual debe ser considerado inocente durante la tramitación de un procedimiento penal" (como se cita en Laveaga y Lujambio, 2007, p. 390), afirmación que reitera la concepción de la presunción como el derecho del imputado a ser tratado como inocente.

De esta manera podemos afirmar que la presunción de inocencia posee 
en sí misma una naturaleza dual, como principio y como derecho, porque es susceptible de ser maximizado como cualquier otro principio, y a la vez es susceptible de reclamar del Estado su respeto individual.

\section{Presunción de inocencia en materia penal}

Internacionalmente, la presunción de inocencia se expresa de formas esencialmente iguales, consiste en considerar a la persona inocente mientras no se establezca su culpabilidad conforme a la ley y mediante sentencia. La reforma constitucional en nuestro país de junio de 2008, trajo consigo pocos cambios en la concepción del derecho a la presunción de inocencia. A partir de ese año se reconoció de manera expresa esta presunción que, hasta el 2002, solo había sido reconocida jurisprudencialmente como un derecho fundamental implícito en otros artículos constitucionales (SCJN, 2002, Tesis P. XXXV/2002 (9a)). Ahora, en el discurso jurídico ya se puede citar directamente una disposición Constitucional, y en el argumento ahora se apela a la fuerza que la Carta Magna representa.

El sentido y significado de este concepto ha sido recientemente definido y consensado por parte de la Suprema Corte de Justicia de la Nación -aunque no por unanimidad- considerándolo como un derecho multifacético o poliédrico, a partir de esta declaración la presunción de inocencia fue dividió en tres reglas con la intención de entenderlo y de aplicarlo. Nótese aquí como es que la presunción de inocencia ha descendido del campo indeterminado de los principios, al espectro de los derechos subjetivos desembocando finalmente en el terreno de las "reglas" específicas. Cada una de las tres reglas tiene su propio contenido, como se muestra a continuación:

I. Regla de trato: esta faceta incluye: (a) el derecho a del imputado a recibir la consideración y el trato de "no autor" o de "no participe", (b) a priori, el sujeto no puede ser considerado como quien cometió la falta que se le imputa y (c) derecho a que se le trate como inocente, hasta que no se demuestre lo contrario. II. Regla probatoria: (a) se reconoce el derecho del imputado a un trato especial dentro del sistema de carga de la prueba, (b) la carga de la prueba recae sobre la 
autoridad, respecto de la comisión de la infracción/falta y (c) la carga de la prueba recae sobre la autoridad y no sobre la probable responsable. III. Regla de juicio (o estándar de prueba): (a) derecho a que se despliegue una actividad probatoria que destruya la presunción de inocencia de forma clara y profunda y (b) que exista un acervo probatorio suficiente.

La jurista colombiana Mónica Bustamante (2010), desarrolla estas tres reglas de una manera aún más precisa:

I. Regla de trato: incluye: (a) que la detención preventiva -como medida cautelar- proceda únicamente cuando se cumplan los requisitos señalados en la ley; (b) que la finalidad de la detención preventiva nunca coincida con el cumplimiento anticipado de la pena, (c) que las personas detenidas permanezcan alejadas de las privadas de la libertad en razón del cumplimiento de una pena de prisión.

II. Regla probatoria: (a) debe existir una actividad probatoria suficiente -en contraposición con la simple sospecha- para la obtención del convencimiento judicial más allá de toda duda razonable, (b) debe existir la prueba de cargo la cual debe recaer sobre la existencia del hecho y la participación en él del acusado - prueba directa e indirecta- (c) la acusación debe suministrar pruebas y producir una actividad probatoria, toda vez que al acusado se le permite permanecer inactivo sin que la sola falta de pruebas de descargo pueda actuar en su contra, (d) la prueba debe ser practicada en juicio oral cumpliendo con el principio de contradicción, (e) las pruebas practicadas deben respetar las garantías procesales y los derechos fundamentales, excluyendo aquellas pruebas obtenidas con violación a estos.

III. Regla de juicio (o estándar de prueba): (a) no se debe incurrir en errores de apreciación probatoria sobre hechos, errores tales como: el falso juicio de existencia, cuando omite apreciar una prueba que obra en el proceso, o supone la existencia de un medio de prueba sin estarlo; falso juicio de identidad, se incurre en el cuándo se considera legal y oportunamente recabada una prueba, pero al fijar su contenido este se distorsiona, cercena o adiciona en 
su expresión fáctica, haciéndole producir efectos que objetivamente no se establecen en ella; falso raciocinio, ocurre al asignarle valor racional a una afirmaciones con mero valor persuasivo transgrediendo los postulados de la lógica y de la ciencia, así como las reglas de la experiencia, es decir, de la sana crítica. (b) No se debe incurrir en errores de apreciación probatoria de derecho como los son: el falso juicio de legalidad, cuando se acepta la prueba no obstante ha sido aportada con violaciones de las formalidades legales para su aducción o la rechaza porque a pesar de estar reunidas dichas formalidades considera que no las cumple; falso juicio de convicción, cuando el juzgador desconoce el valor prefijado a la prueba de la ley, o la eficacia que ésta le asigna, en este último apartado cabe mencionar que la valoración de la prueba en el derecho penal no es tasado.

En la voz de Joaquin Fortún Basaurí (como se cita en Laveaga y Lujambio, 2007, p. 392), la presunción de inocencia en materia penal, representa el deber de la legislación adjetiva penal de salvaguardar siempre este derecho en aspectos como la prisión preventiva, libertad caucional, carga de la prueba, prueba insuficiente, valoración de pruebas, juicio breve, e incluso, indemnización a las personas que hayan sido ilegalmente detenidas y sancionadas (incriminación primaria). Por su parte, el juzgador debe aplicar la ley considerando en todo momento esta garantía y sus efectos en el proceso (incriminación secundaria).

\section{Presunción de inocencia del proceso penal al proceso administrativo sancionador}

\section{a) Posiciones en contra}

Quienes se oponen a la expansión, de esta presunción hacia la materia administrativa, sostienen su postura en argumentos claramente identificables: i) previsión expresa: constitucionalmente el derecho a la presunción de inocencia está previsto en favor de la persona imputada en el marco del proceso penal (CPEUM, 2018, art. 20.I.B) y no para el derecho administrativo, ii) diferencia 
estructural: la trilogía procesal penal está compuesta por el juez, el ministerio público y el imputado, por lo que existe "una relación jurídica procesal en donde dos contrarios someten a un tercero la determinación de un veredicto" (SCJN, 2014 , p. 6), lo que hacen de manera oral, esto no ocurre con los actos unilaterales que emite la administración en materia sancionatoria, los cuales se instruyen de manera escrita, en donde un mismo órgano o autoridad es órgano acusador, instructor y sancionador al mismo tiempo, lo que en términos del jurista español Perfecto Andrés Ibáñez, no cumple con la precondición primaria estructural del derecho a la presunción de inocencia como garantía (como se cita en Bustamante, 2010, p. 74). iii) la interpretación gramatical y literal del artículo 21, constitucional, apartado B, punto I, no permiten extender su contenido al derecho administrativo, por lo que su alcance está limitado y restringido al derecho penal lo que excluye al derecho a la presunción de inocencia del proceso administrativo sancionador, iv) interpretación auténtica, histórica y teleológica: el derecho a la presunción de inocencia nació por y para el derecho penal exclusivamente.

\section{b) Posiciones a favor}

Quienes abogaron por reconocer la presunción de inocencia en el proceso administrativo sancionador reconocieron en el artículo $1^{\circ}$ Constitucional la posibilidad de emplear el principio hermenéutico pro persona, para maximizar la protección de los derechos. Vieron en la interpretación evolutiva y en el fenómeno de mutación de derechos la oportunidad de que aquella disposición constitucional que literalmente dice "penal", se entienda, no solo al derecho penal, sino a la potestad sancionadora del Estado, y con este enfoque, dar cabida también al derecho administrativo sancionador.

Debemos tener presente que el derecho administrativo sancionador estudia lo relativo a la potestad sancionadora de la administración, la cual se puede definir como "... una atribución propia de la administración que se traduce en la posibilidad jurídica de la imposición de sanciones a los particulares y aún a los funcionarios que infringen sus disposiciones, o a sus servidores que, en el ejercicio de sus funciones, transgreden sus mandatos o desconocen sus prohibiciones." (Góngora, 2006, p. 257). 
Durante una sesión pública ordinaria del pleno de la Suprema Corte de Justicia de la Nación, celebrada el martes 28 de enero de 2014, se discutieron diversas posturas que una vez ordenadas se podrían exponer de la siguiente manera (SCJN, 2014, p. 4): a) La potestad administrativa sancionadora, al igual que la potestad penal, forman parte de un genérico punible del Estado, entonces la presunción de inocencia constituye un límite a la potestad represiva del Estado en ejercicio de su derecho punitivo. b) La presunción de inocencia como principio constitucional, es de aplicación general y debe atender a la protección de la persona (SCJN, 2014, p. 4), por lo que debe proteger a la persona en el procedimiento administrativo sancionador. c) Reconocer esta presunción produce más seguridad jurídica a los involucrados en el procedimiento, y constituye una medida apropiada ante las exigencias del modelo de Estado Constitucional Democrático. d) Su aceptación en el procedimiento administrativo sancionador, deviene de la interpretación sistemática y armónica de los instrumentos internacionales y de nuestra Ley Suprema Nacional, el principio de interpretación más favorable a la persona interconecta la obligación del Estado de observar el debido proceso, la legalidad, la seguridad jurídica a la que se debe apegar, con miras a respetar, proteger y garantizar el ejercicio de la defensa adecuada, por ello, el reconocimiento de la presunción de inocencia se ha convertido en un elemento indispensable, imprescindible, e inamovible por el principio de progresividad de los derechos, por lo que, el espectro amplificador del principio de presunción de inocencia debe irradiar en el proceso administrativo.

En el plano internacional contamos con tres referentes, el primero de ellos surgió con motivo del caso López Mendoza vs. Venezuela la Corte Interamericana de Derechos Humanos estudió un procedimiento administrativo sancionador, en el cual abordó la presunción de inocencia como un principio, y lo relacionó con el deber de garantías judiciales y el derecho de defensa. Retomó el contenido de esta presunción del derecho penal y afirmó que este principio “...implica que los juzgadores no inicien [en] el proceso con una idea preconcebida de que el acusado ha cometido el delito que se le imputa acusado...", (CrIDH, 2011, p. 51) mientras que este último "... no debe demostrar que no ha cometido el delito que se le atribuye" (CrIDH, 2011, p. 50), ya que el "onus probandi corresponde 
a quien acusa". En este caso la Corte absolvió al Estado venezolano al concluir que no se comprobó que el Estado haya violado la presunción de inocencia (véase CrIDH, 2011, p. 52). Al respecto, cabe resaltar que fundamentó su decisión en el debido proceso previsto en el artículo 8.1 del Pacto de San José Costa Rica (Convención Americana sobre Derechos Humanos, 1969), y no en la presunción de inocencia en materia penal contenida en el artículo 8.2.

En segundo lugar, el Caso Baena Ricardo y otros vs. Panamá (CrIAH, 2001), relacionado con el despido arbitrario a 270 empleados públicos por la vía administrativa, fue resuelto por la Corte Interamericana en el sentido de condenar al Estado miembro, para ello fundó su decisión en la falta de solidez del material probatorio que el Estado empleó para motivar el despido controvertido. Esta ausencia probatoria le permitía a la Corte condenar al Estado en base a la violación directa a la presunción de inocencia, sin embargo la resolución final condenó al Estado por la inexistencia misma de un procedimiento previo, de ahí que la Corte optó por no analizar a la presunción de inocencia administrativa ni sus particularidades.

En tercer lugar, el Tribunal Europeo de Derechos Humanos se ha pronunciado sobre este tema en Albert and Le Compte v. Belgium relacionado con la inhabilitación administrativa de médicos Belgas (TEDH, 1983, 7299/75), en donde señaló que "toda persona acusada de una infracción se presume inocente hasta que su culpabilidad haya sido legalmente declarada" (Convenio Europeo de Derechos Humanos, 1950, art. 6.2), lo cual está contenido en el Convenio Europeo de Derechos Humanos, pero preciso que:

"... the principles set out in paragraph 2 (art. 6-2) and in the provisions of paragraph 3 invoked by Dr. Albert (that is to say, only sub-paragraphs (a), (b) and (d)) (art. 6-3-a, art. 6-3b, art. 6-3-d) are applicable, mutatis mutandis, to disciplinary proceedings subject to paragraph 1 (art. 6-1) in the same way as in the case of a person charged with a criminal offence."'(TEDH,

1 “... los principios enunciados en el párrafo 2 (art. 6-2) y 3 (a saber los incisos a, b y d) [... de la Convención Europea de Derechos Humanos], se aplican mutatis mutandis a los procesos disciplinarios a los que se refiere el inciso 1 (art. 6-1) de la misma forma en que se aplican a los casos en que una persona es acusada por una 
$1983,7299 / 75)$

Por lo que, para ese Tribunal "el principio" de presunción de inocencia es aplicable mutatis mutandis a los procesos disciplinarios, cambiando lo que debe ser cambiado, de la misma manera que en aquellos casos en que una persona es acusada por una infracción penal. Esto coincide con la determinación nacional mexicana de aplicar esta presunción con matices y modulaciones en los procesos disciplinarios administrativos.

Con todas estas consideraciones, el derecho de presunción de inocencia debe ser tomado en cuenta también por las autoridades materialmente administrativas, cuyos actos se materialicen en forma de procedimientos administrativos, cuando su objeto sea el de imponer una sanción pero "con matices o modulaciones" (SCJN, 2014, Tesis P./J. 43/2014 (10a)).

A esto se puede añadir que, si bien el diseño procesal del derecho penal y del derecho administrativo son distintos, esta condición adjetiva no afecta el reconocimiento de la presunción de inocencia, pues al inicio de esta exposición se fijó que esta presunción es un derecho fundamental, por lo que su eficacia no está condicionada a un diseño procesal determinado.

\section{Presunción de inocencia. Sus matices y modulaciones}

\section{a. Tres modelos para realizar matices y modulaciones}

Hacer el traslado del derecho a la presunción de inocencia del derecho penal al derecho administrativo sancionador requiere procesos claros, por ello se plantearán tres posibilidades:

El primero de ellos es el predilecto por cualquier gobernado, lo llamaremos

infracción de carácter penal." trad. Corte Interamericana de Derechos Humanos (2001), Corte Interamericana de Derechos Humanos (2001), Caso Baena Ricardo y otros vs. Panamá, Excepciones Preliminares, Fondo y Reparaciones, Sentencia de 2 de febrero de 2001, recuperado de http://www.corteidh.or.cr/docs/casos/articulos/ Seriec_72_esp.pdf, consultado el 16 de enero de 2018, p. 128. 
modelo de identidad, y se reduce en afirmar que todos los efectos los efectos protectores de esta presunción en la materia penal se trasladan hacia la materia administrativa sancionadora. Esta propuesta requiere aceptar unánimemente dos proposiciones: la presunción de inocencia es un dogma penal, y como dogma no admite ningún grado de intensidad, matiz, graduación ni modulación, por lo que se rige en términos de todo o nada, y en segundo lugar tendríamos que aceptar que existe una identidad entre el derecho administrativo y el derecho penal, esto para poder justificar, desde la unidad de origen, la identidad de propiedades y con ello la unidad de consecuencias, sin embargo, que ambas sean expresiones de la facultad punitiva del Estado (SCJN, 2015, Tesis: PC.I.A. J/52 A (10a)) no es razón suficiente para justificar esta postura, ya que, mientras que en el contexto del derecho penal la presunción de inocencia protege el valor de su libertad, que tiene como objeto proteger el desarrollo de sus potencialidades del individuo (García, 1990, p. 23), el procedimiento administrativo sancionador, tiene como finalidades el determinar responsabilidades y el imponer sanciones a causa de la comisión de conductas ilícitas, faltas o infracciones en materia administrativa, sin afectar la libertad individual, por lo que, al proteger valores distintos, las consecuencias de una presunción de inocencia no pueden ser idénticas.

Un segundo modelo lo llamaremos modelo de dependencia, consistiría en aceptar que no todos los efectos protectores de esta presunción en la materia penal se trasladarán hacia la materia administrativa sancionadora. El modelo parte de reconocer y aceptar como punto de partida la presunción de inocencia penalista en su integridad, con la tarea de fijar tantas excepciones como resulten necesarias para mantener vivos los postulados de la dogmática administrativa que le permita seguir operando con eficacia, y en aquellas expresiones sin excepciones expresas, se entenderá que se aplicarán de manera idéntica. Sin embargo, este modelo de dependencia no permitiría adicionar elementos nuevos al concepto, por lo que el derecho administrativo sancionador siempre estaría un paso atrás del derecho penal, así, cada cambio en el primero será motivo de análisis y discusión en el segundo.

Finalmente, tenemos el modelo de independencia que consistiría en afirmar que solo algunos de los efectos protectores de esta presunción en la 
materia penal se trasladarán hacia la materia administrativa sancionadora, ello nos obligaría a reformular el contenido y alcances de la presunción de inocencia en materia administrativa, con la posibilidad de integrarla con algunos precedentes dictados en el ámbito del derecho penal porque ambas materias tienen en común que sus reglas se justifican en el control y delimitación de la facultad punitiva del Estado (Góngora, 2006, p. 227), pero con la apertura a nuevas ideas y modalidades. La diferencia entre esta propuesta y la anterior, es que aquí el trasiego de características no es automático, al contrario, existe la tarea de tener que justificar la integración de cada criterio del derecho penal al derecho administrativo, cada vez que se estimen necesarios y compatibles.

No obstante que las materias penal y administrativa tenga una base común, se estima que estas materias son autónomas, lo que se confirma con un claro desarrollo dogmático, legislativo e institucional independientes y hace que tengan notables diferencias. Por esta razón, se optará por seguir el modelo independiente, por lo que solo algunas de las reglas de esta presunción serán aplicables al derecho administrativo sancionador, y son estas últimas las que serán matizadas o moduladas, según el caso.

\section{b. Presunción de inocencia desde el modelo independiente}

La Suprema Corte de Justicia de la Nación estableció en términos generales los lineamientos para establecer matices y modulaciones a la presunción de inocencia. Expuso que debían hacerse “...matices y modulaciones [a esta presunción] debido a su naturaleza gravosa..." (SCJN, 2014, Contradicción de tesis 200/2013), también apuntó que “...su incorporación al procedimiento administrativo sancionador debe ser prudente ya que solo son aplicables en la medida en que sean compatibles con su naturaleza..." (SCJN, 2006, Tesis: P./J. 99/2006 (9a)), y que debían ser “...administra[das] con la pluralidad del caso (sic)..." (SCJN, 2014, p.17) por lo que “...su empleo debe ser según el caso..." (SCJN, 2014, p. 28) y optó por no ahondar en detalles al considerar como “... extraordinariamente complicado establecer una especie de catálogo minucioso de cada caso... [y] porque podríamos limitar las posibilidades, interpretativas 
de los juzgadores, y por el otro lado, tendríamos que idear e imaginar todos los supuestos posibles de procedimientos para establecer estos lineamientos..." (SCJN, 2014, p. 29).

Ahora bien, cabe aclarar que los "matices" y "modulaciones" son conceptos extralegales. Mientras que los matices se refieren al "grado o variedad que no altera la sustancia o esencia de algo" (DRAE, 2018), las modulaciones consisten en "modificar los factores que intervienen en un proceso para obtener distintos resultados" (DRAE, 2018).

Así, en la presunción de inocencia nos referiremos a un matiz cuando hagamos cambios en la expresión de términos jurídicos para adecuarlos de una materia a la otra, pero conservando los efectos de la regla, por ejemplo, en lugar de hablar de probable responsable, nos referiremos a probable infractor, de esta manera el cambio es solo terminológico, mientras que en el fondo los dos se refieren a la presunción de inocencia en su expresión de regla de trato. Por otra parte, entenderemos a las modulaciones como una variación en el grado de aplicación de la regla, como puede ser la reducción del estándar probatorio de una materia a otra. Así, cuando el punto de partida penal sea un grado de convicción más allá de toda duda razonable, se aplicará la máxima in dubio pro reo ante “... dos alternativas que causan la duda" (Henríquez, et. al., 2014: p. 7), mientras que la modulación administrativa consistirá en migrar hacia este estándar probatorio de la prueba prevalente.

\section{Regla de trato}

En aplicación de la presunción de inocencia, podemos plantear un primer matiz si prescindimos de expresiones tales como "presunto infractor" $y$ "presunto responsable", y las sustituimos por expresiones como "probable infractor" o "probable responsable", no estaríamos empleando eufemismos, sino expresiones capaces de convertirse en acciones y transformar la realidad" (Austin y Barthes, 2012), la propuesta parte de la importancia del empleo del lenguaje técnico cuyo significado nos obligue a esforzarnos en mejorar el proceso sancionador 
administrativo como medio para lograr la verdad.

La primera modulación está relacionada al dictado y ejecución de las medidas provisionales, la decisión administrativa que elige una medida cautelar no obedece a una jerarquía previamente reglada. Por su parte, en la materia penal, se prevé el supuesto de la prisión preventiva como medida provisional reglada a ciertos casos previstos por la ley. Esta diferencia permite afirmar que en la materia administrativa, la presunción de inocencia no puede ser empleada para reclamar una medida en lugar de otra.

Otra modulación está en reconocer que el administrado en un procedimiento sancionador deja de ser "inocente" desde que se dicta una sanción, pues pese a no tener firmeza, si adquiere definitividad lo que le permite ejecutarse de manera inmediata, lo cual, desde la teoría del acto administrativo implica que este produce efectos jurídicos directos e inmediatos dada sus características de eficacia, ejecutividad y exigibilidad, esto hasta en tanto su nulidad no sea decretada por la autoridad jurisdiccional competente.

Estas dos últimas modulaciones impactan de manera directa los alcances de la presunción de inocencia. Si el particular está inconforme con una medida cautelar o una sanción ordenada por la autoridad administrativa, y aspira a reclamar de la autoridad su sustitución por una menos gravosa o pretende suspender la sanción los posibles daños y perjuicios, el argumento de la presunción de inocencia que le reconoce el trato de inocente no operaría en los términos pretendidos por el peticionario, porque el Estado en su discrecionalidad puede negar la sustitución o la garantía ofrecida oponiendo que de hacerlo ello "contravendría disposiciones de orden público" (TFJFA, 2013, 1747/13-09-01-2).

\section{Regla probatoria}

En todo caso, la carga de la prueba recae sobre la autoridad, pero la expresión de regla se puede matizar si hacemos aquellos cambios en el empleo de términos jurídicos, afirmando que la autoridad debe probar la comisión de la infracción o falta, para evitar referirnos a la comisión de delitos., en el mismo sentido podemos sustituir la expresión de presunto infractor para referirnos a él 
como probable responsable.

En relación al estándar exigible a la autoridad para llamar al procedimiento sancionador al gobernado no hay lugar para hacer una modulación, pues conceptualmente el derecho administrativo sancionador no dista esencialmente de la materia penal, esto es así si tomamos en cuenta que el artículo 16 párrafo primero constitucional exige en la materia penal que existan datos que establezcan que se ha cometido un hecho que la ley señale como delito y la probabilidad de que el indiciado lo haya cometido o participado en su comisión, mientras que en la materia administrativa para llamar al gobernado al inicio del procedimiento deben "existir pruebas de cargo suficientes que permitan a la Administración deducir un juicio de reproche razonadamente" (Ruiz, 2014).

Por otro lado, a partir de nuestro modelo independiente, se propone la existencia de característica especial de la presunción de inocencia en el procedimiento administrativo, lo que no sería ni un matiz ni una modulación. Esta característica especial permitiría exigir a la autoridad administrativa que no requiera al gobernado aquella información a la que ésta tenga acceso a partir de sus archivos o bases de datos. Así, cuando exista algún elemento que pueda producir una prueba de descargo probatorio en favor del administrado, la autoridad deberá recabarla y desahogarla. Esta condición se fija tomando en cuenta que la administración pública tiene el acceso a bases de datos y archivos propios o en colaboración con otras dependencias, esta información se puede obtener con mayor eficacia y en ocasiones sin costo alguno por la autoridad instructora, por lo que resulta ocioso, desproporcionado y oneroso requerir al particular la documentación que la propia administración produzca, almacene o a la que esta tenga acceso. Por ello, exigirle al particular que despliegue acciones para demostrar su inocencia a partir de información pública resulta desproporcionado, pues debemos partir a priori de la condición jurídica de inocencia del gobernado.

\section{Regla de juicio (o estándar de prueba)}

Como regla probatoria se propone una modulación muy importante en la presunción de inocencia, porque en materia penal el juez debe cerciorarse de que las pruebas de cargo desvirtúen la hipótesis de inocencia efectivamente 
alegada por la defensa en el juicio, y en caso de que existan pruebas de descargo o contraindicios, debe cerciorarse que estos no den lugar a una duda razonable sobre la hipótesis de culpabilidad, de lo contrario debe poner en acción la máxima in dubio pro reo.

Al respecto, merece la pena ahondar en el concepto fundamental en el derecho penal que consiste en el estándar de prueba que exige producir una convicción más allá toda duda razonable. Este concepto es de origen anglosajón, y exige un nivel de convicción muy alto para declarar la culpabilidad de una persona respecto de su participación en determinados hechos. Mientas que en el derecho anglosajón esta labor está asignada a un jurado de ciudadanos, en el derecho mexicano la valoración probatoria está asignada a la autoridad judicial.

Este estándar se compone de tres criterios delineados por Elisabeth Stoffelmayr quien comienza por afirmar que la certeza absoluta no debe ser exigida, pues todo en cuanto pretende ser demostrado se acredita con cierto grado de probabilidad, nunca con una certeza matemática absoluta $(2000$, p. 1) lo que nos lleva al segundo elemento que afirma que la ausencia de certeza absoluta no implica que una condena ocurra sin una fuerte evidencia que produzca un alto grado de certeza de que el acusado es culpable (2000, p. 3). Como tercer elemento tenemos que este estándar debe ser distinguido de estándares más bajos de prueba, como ocurre en la materia civil en los Estados Unidos donde en casos cuasicriminales tiene lugar el estándar de prueba clara, inequívoca y convincente, que se traduce en la existencia de evidencia suficientemente persuasiva para creerla. En otros casos civiles el nivel de persuasión requerido es aún menor y se exige la aplicación del estándar de preponderancia de la prueba. Con estas diferencias, el estándar de prueba más allá de toda duda razonable para Elisabeth Stoffelmayr exigiría un $90 \%$ o 95\% de convicción.

Este grado de convicción exige que las pruebas dejen al juzgador firmemente convencido de la culpabilidad del imputado. Que sea más allá de "toda" duda razonable no significa que tenga que sobrepasar toda duda "posible", pues para ello también es necesario calificar el valor de la duda, así no puede calificarse a cualquier duda "posible" como duda razonable. La duda no puede 
ser derivada de una mera conjetura, ni una elaborada o trivial suposición, o nacer de la una simple posibilidad de inocencia (Stoffelmayr; 2000, p. 3), tiene que existir, a partir de la evidencia, una posibilidad real de que el imputado no sea culpable, es esa duda la que resulta relevante para emplear la máxima in dubio pro reo la cual se enuncia para declarar al imputado como inocente.

Hechas estas aclaraciones, debe tenerse en cuenta que en el procedimiento administrativo sancionador el estándar probatorio será el de prueba prevalente, no el de grado de convicción más allá de toda duda razonable., de ahí que la máxima in dubio pro reo no le resulte aplicable. En términos analíticos señala Michele Taruffo que "... una situación verdaderamente clara sólo se tiene con valores de probabilidad que oscilan entre el 55-60\% y valores superiores... alrededor del $70 \%$..." (Taruffo, 2009, p. 110), lo que significa que la autoridad administrativa podrá sancionar cuando sea verdaderamente cierto que "la probabilidad de un enunciado es prevalente sobre la probabilidad de su falsedad" (2009, p. 111).

Lo que si podemos afirmar en ambas materias es que se debe contar con evidencias para emitir un juicio de valor, sin ser válidas las meras conjeturas o indicios de probabilidad, por lo que "cualquier juicio valorativo de la prueba [que] se manifieste arbitrario o carente de conexión lógica con el contenido probatorio" (Tribunal Constitucional de España, 1990, 138/1990) vulnerará este derecho a la presunción de inocencia.

Una vez expuesto que entre la materia penal y administrativa hay estándares probatorios distintos, sigue el turno de exponer como opera la presunción de inocencia cuando se interpreta normativamente una infracción, pues de esta interpretación surgirán cuales son los hechos esenciales que deben acreditarse para tener por actualizada la infracción y poder entonces imponer una sanción.

En estos términos, cuando se integra un tipo penal o una infracción administrativa se produce una interpretación que puede restringir o ampliar los límites de la norma, esto exige hacer una modulación. Mientras que la integración normativa de un tipo penal es de tipo restrictivo por la prohibición de la analogía y mayoría de razón, en la materia administrativa la integración normativa de 
las infracciones puede hacerse a partir de normas reglamentarias, quedando autorizada la analogía y la mayoría de razón, e incluso la sanción de conductas atípicas. Estos tipos de integración son la precondición para fijar si las pruebas han sido idóneas, suficientes y eficaces para acreditar la conducta, de no ser así, la autoridad resolverá una absolución a partir de la ausencia o la deficiencia probatoria del órgano acusador.

Brevemente se puede afirmar que entre la materia penal y la administrativa existe el mismo deber de no incurrir en errores de apreciación probatoria de hecho, por lo que se debe evitar el falso juicio de existencia, el falso juicio de identidad, y el falso raciocinio.

Finalmente se afirma que existe una modulación que separa a la materia penal de la administrativa respecto de las reglas de derecho con las que se valoran las pruebas en una materia y en otra. Esto se debe a que en la materia penal la regla de derecho permite valorar las pruebas de manera libre y lógica (CNPP, 2018, art. 259), por el contrario en la materia administrativa los documentos públicos tienen un valor tasado, lo que les dota de una presunción de validez iuris tantum, esto significa que en materia administrativa estos documentos harán prueba plena en tanto no haya prueba en contrario. Este fenómeno se debe a que nuestro derecho administrativo resulta ser eminentemente escrito, de ahí que este tipo de pruebas tenga importantes consecuencias en la decisión final y en la manera de entender la presunción de inocencia.

\section{Confesión ficta}

Se plantea la necesidad de modular la presunción de veracidad o de certeza de la administración, los documentos expedidos por una autoridad en el cumplimento de sus funciones tienen una fuerza probatoria privilegiada porque serán válidos salvo prueba en contrario lo que opera en pro de la autoridad. Al respecto el Tribunal Constitucional español a través de su doctrina estableció que las pruebas producidas por la autoridad no tienen como finalidad “...la fijación definitiva de los hechos para que éstos transciendan a la resolución judicial...” (Sentencia 
217/1989).

De ahí que convenga hacer una modulación respeto al derecho a la presunción de inocencia del administrado para volcar la valoración en pro del individuo, exigiendo una "previa actividad probatoria sobre la cual el órgano competente pueda fundamentar un juicio razonable de culpabilidad" (Tribunal Constitucional de España, 1990, 138/1990) conteniendo los efectos desmesurados que produce la confesión ficta que actualmente opera en contra del gobernado, y en pro de la autoridad.

En materias como la civil, mercantil y laboral el demandado que omite dar contestación a la demanda interpuesta en su contra, bajo ciertas condiciones, lo llevará a que la autoridad lo califique de contumaz o rebelde, y se le sancione procesalmente con tenerle por confesados y ciertos aquellos hechos que se le atribuyen y en su momento a que se le condene. No obstante lo anterior, si bien es cierto el Código Federal de Procedimientos Civiles es supletorio de la Ley Federal del Procedimiento Administrativo (LFPA, 2018, art. 2), esto no representa que aquella supletoriedad pueda aplicarse en perjuicio del derecho a la no autoincriminación que forma parte de la presunción de inocencia penal, pues la regla de la confesión ficta resulta contraria a la naturaleza del procedimiento administrativo sancionador, pues son más las similitudes de este procedimiento con el derecho procesal penal, que las similitudes que pudiera tener con el procedimiento de derecho civil.

Por lo anterior, se señala con preocupación que el régimen de supletoriedad del derecho administrativo sancionador con el derecho procesal civil pueda impactar en forma negativa el grado de convicción necesario para resolver. De seguir con esta supletoriedad resultaría muy sencillo a la autoridad administrativa el poder vencer la presunción de inocencia con una ficción legal que autorice a tener por probada la culpabilidad del probable responsable. El estándar de probabilidad prevalente, en términos del jurista italiano Michele Taruffo, exige la "exposición de criterios intersubjetivamente controlables... eliminando toda implicación irracional" (2009, p. 103) lo que no se cumple si solo se condena en base a una confesión ficta. 
En la segunda instancia, hay un matiz entre la presunción de inocencia administrativa y la presunción de origen penal, pues ambos coinciden en que para respetar esta presunción de inocencia se deben analizar los juicios valorativos de la prueba, pues la existencia de un juicio "arbitrario o carente de conexión lógica con el contenido probatorio" (Tribunal Constitucional de España, 1990, 138/1990) constituiría, en ambas materias, una violación a la presunción de inocencia y en ambos casos podrán absolver al sancionado en segunda instancia, decretando la revocación o la nulidad de la resolución, según la materia.

\section{Operadores del derecho}

La presunción de inocencia ya está reconocida en ambas materias, pero "la existencia de una norma [de fuente legal o jurisprudencial] no garantiza por sí misma que su aplicación sea adecuada". (CrIDH, 2011, 92) Siguiendo a Joaquin Fortún Basaurí (como se cita en Laveaga y Lujambio, 2007, p. 392) la presunción de inocencia “...debe ser respetada por el legislador en el proceso de creación de leyes, [...] así como por las autoridades judiciales [y administrativas] en la aplicación de las mismas...".

En el génesis de esta presunción reconocida en el derecho administrativo sancionador se previó la resolución caso por caso, esto significa entonces que su “...interpretación dependerá de cada actor del sistema...” (Delége, 2015, p. 26), servidores públicos, jueces y magistrados.

$\mathrm{Si}$ consideramos que, para las autoridades administrativas no es obligatorio acatar la jurisprudencia nacional, pues no es obligatoria hacia ellas en términos de la Ley de Amparo (2018, art. 217), y que la vinculatoriedad de la jurisprudencia emitida por la Corte Interamericana ayuda poco al desarrollar con suficiente previsión este rubro, no nos queda más que exigir a las autoridades administrativas que hagan control de convencionalidad al nivel de selección normativa e interpretativa, aplicando la norma y la interpretación que resulte más favorable para la persona. También se considera necesario el desarrollo de procedimientos administrativos sancionadores sobre la base de precedentes

\section{DERECHO GLOBAL. ESTUDIOS SOBRE DERECHO Y JUSTICIA}


judiciales que, aunque no sean obligatorios, se tomen en consideración a partir de su valor persuasivo y razonable, esto con el objetivo de adherir y vincular voluntariamente a la administración a esta corriente.

En este proceso, la formación de los operadores jurídicos es un factor de gran importancia para conseguir una adecuada concepción y aplicación de la presunción de inocencia en el sistema, por ello un consenso es indispensable para ayudar a proteger al administrado contra la potencial arbitrariedad que se pueda manifestar en un procedimiento administrativo sancionador, sin afectar la contundencia de las sanciones contra los actos ilícitos.

\section{Conclusiones}

La presunción de inocencia no es un elemento aislado, se interrelaciona con otros derechos sustantivos y adjetivos del gobernado, por lo que su violación no ocurre directa ni aisladamente, se actualiza siempre de manera simultánea con otras violaciones procesales al debido proceso y a la legalidad.

Se deben discutir con mayor intensidad los alcances de la presunción de inocencia en el procedimiento administrativo sancionador. Se advierte que la regla general actualmente consiste en aplicar la presunción de inocencia a la materia administrativa de la misma manera en la que se aplica en el derecho penal, la causa de este fenómeno radica en la simplicidad de esta operación y en lo limitado de un estudio, discusión y enseñanza claramente diferenciados.

El desarrollo de esta presunción de inocencia en materia administrativa requiere de un progresivo y constante desarrollo doctrinal y jurisprudencial que en conjunto permita alinear los esfuerzos de los operadores jurídicos por hacer cumplir de manera eficaz el sistema de sanciones sin abusos por parte de la autoridad.

La presunción de inocencia y el combate a la corrupción en la agenda pública mexicana estarán sin duda inmersos en muchos enfrentamientos. La promesa política de un sistema de sanciones administrativos contundente genera 
una expectativa de sanción a todo infractor (cero impunidad), ante este objetivo, el desarrollo técnico jurídico debe evolucionar para estudiar el tema a profundidad, generar doctrina nacional y dejar claras las reglas para reducir la discrecionalidad en la aplicación de este derecho a la presunción de inocencia.

Actualmente el porcentaje de sanciones tiende a cero. Una las razones técnico jurídicas que ocasiona la ineficacia del sistema consiste es la falta de soluciones probatorias, pero la presunción de culpabilidad no es la salida. Se necesita voluntad para construir un sistema eficiente, pero también se requiere esfuerzo para hacerse de las herramientas y conocimientos necesarios para poder hacerlo realidad, sin ello el fracaso está garantizado.

\section{Bibliografía}

Bustamante Rúa, Mónica María (2010), "La relación del estándar de prueba de la duda razonable y la presunción de inocencia desde el garantismo procesal en el Proceso Penal Colombiano", Opinión Jurídica, vol. 9, no. 17, pp. 71-91, recuperado de http://revistas. udem.edu.co/index.php/opinion/article/view/80/64, consultado el 27 de diciembre de 2018.

Código Nacional de Procedimientos Penales, (2018), recuperado de http://www.diputados.gob.mx/LeyesBiblio/pdf/CNPP_170616.pdf, consultado el 07 de febrero 2018.

Convención Americana sobre Derechos Humanos, (1969), recuperado de https://www.oas.org/dil/esp/tratados_b-32_convencion_americana sobre_derechos_humanos.htm, consultado el 30 de enero de 2018.

Convenio Europeo de Derechos Humanos (1950), recuperado de https:// www.echr.coe.int/Documents/Convention_SPA.pdf, consultado el 28 de enero de 2018.

Constitución Política de los Estados Unidos Mexicanos, (2018), recuperado de http://www.diputados.gob.mx/LeyesBiblio/ pdf/1_150917.pdf, consultado el 07 de enero 2018. 
Corte Interamericana de Derechos Humanos (2001), Caso Baena Ricardo y otros vs. Panamá, Excepciones Preliminares, Fondo y Reparaciones, Sentencia de 2 de febrero de 2001, recuperado de http://www.corteidh.or.cr/docs/casos/articulos/Seriec_72_esp.pdf, consultado el 16 de enero de 2018.

Corte Interamericana de Derechos Humanos, (2011), Caso López Mendoza vs. Venezuela, Excepciones Preliminares, Fondo y Reparaciones, Sentencia de 1 de septiembre de 2011, recuperado de http://corteidh. or.cr/docs/casos/articulos/seriec_233_esp.pdf, consultado el 14 de enero de 2018.

Corte Interamericana de Derechos Humanos, (2011), Caso Radilla Pacheco vs. Estados Unidos Mexicanos, Excepciones Preliminares, Fondo y Reparaciones, Sentencia de 23 de noviembre de 2009, recuperado de http://www.corteidh.or.cr/docs/casos/articulos/ seriec_209_esp.pdf, consultado el 19 de enero de 2018.

Council of Europe: European Court of Human Rights, (1983), 7299/75; 7496/76, Albert and Le Compte v. Belgium, 28 January 1983, recuperado de: http://www.refworld.org/cases,ECHR,3ae6b6f510. html, consultado el 12 de febrero de 2018.

Declaración Universal de los Derechos Humanos, (1948), recuperado de http:/www.un.org/es/universal-declaration-human-rights/, consultado el 12 de enero de 2018.

Deléage Elsa, (2015), « La Loyauté de l'administration », Revu Générale de Droit, núm. 18966, recuperado de www.revuegeneraledudroit. eu/?p=18966, consultado el 15 de enero de 2018.

Durán M., Augusto (2007), La presunción de legitimidad del acto administrativo. Un mito innecesario y pernicioso, (artículo en línea), recuperado de: https://dialnet.unirioja.es/descarga/articulo/2531910. pdf, consultado el 23 de agosto de 2018.

Góngora Pimentel Genaro David, (2006), "El Reconocimiento del Derecho Administrativo Sancionador en la Jurisprudencia Constitucional Mexicana" en Eduardo Ferrer Mac-Gregor y Arturo Zaldívar Lelo de Larrea (coords.), La ciencia del derecho procesal 
constitucional, (pp. 255-274), México, IIJ, UNAM, recuperado de https://archivos.juridicas.unam.mx/www/bjv/libros/6/2564/17.pdf, consultado el 06 de febrero de 2018.

García Ramírez Sergio, (1990), Derecho Penal, México, Porrúa.

Henríquez Salido María do Carno, et. al., (2014) "La fórmula in dubio en la jurisprudencia actual" Revista de Llengua I Dret, núm. 62, pp. 6-22, doi: http://dx.doi.org/10.2436/20.8030.02.75, consultado el 12 de diciembre de 2017.

Laveaga Gerardo y Lujambio Alberto Coords. (2007), El Derecho Penal a Juicio, Diccionario Crítico, México, Instituto Nacional de Ciencias Penales, Procuraduría General de la República.

Michele Taruffo (2009), La prueba, artículos y conferencias, Chile, Ed Metropolitana, recuperado de https://letrujil.files.wordpress. com/2012/01/la-prueba-michele-taruffo.pdf, consultado el 18 de enero de 2018.

Real Academia Española. (2017). Diccionario de la lengua española (23a ed.). Consultado en http://dle.rae.es/, consultado 23 de febrero de 2018.

L. Austin John, y Barthes Roland, (2012), Performatividad, (artículo en línea), recuperado de: http:/granerbcn.cat/performatividad-1-segunjohn-1-austin-y-roland-barthes/, consultado el 29 de enero de 2018.

Ley de Amparo, Reglamentaria de los Artículos 103 y 107 de la Constitución Política de los Estados Unidos Mexicanos, recuperado de http://www.diputados.gob.mx/LeyesBiblio/pdf/LAmp_190118. pdf, consultado el 15 de diciembre de 2017.

Ley Federal del Procedimiento Administrativo, (2018), recuperado de http://www.diputados.gob.mx/LeyesBiblio/pdf/112_020517.pdf, consultado el 23 de febrero de 2018.

Pacto Internacional de Derechos Civiles y Políticos, (1966), recuperado de http:/www.ohchr.org/SP/ProfessionalInterest/Pages/CCPR.aspx, consultado el 15 de enero de 2018.

Ruiz Mabel (2014), "La Indefensión de los jóvenes frente a las multas por botellón, Parte II, La presunción de veracidad de la 
administración versus la presunción de inocencia del administrado" Lawyerpress, recuperado de http://www.lawyerpress.com/ news/2014_09/1709_14_009.html, consultado 02 de diciembre de 2017.

Suprema Corte de Justicia de la Nación, (2002) Tesis P. XXXV/2002, "Presunción de inocencia. El principio relativo se contiene de manera implícita en la constitución federal", Semanario Judicial de la Federación y su Gaceta, Novena Época, t. XVI, agosto de 2002, página 14.

Suprema Corte de Justicia de la Nación, (2006), Tesis: P./J. 99/2006, "Derecho administrativo sancionador. Para la construcción de sus propios principios constitucionales es válido acudir de manera prudente a las técnicas garantistas del derecho penal, en tanto ambos son manifestaciones de la potestad punitiva del Estado", Semanario Judicial de la Federación y su Gaceta, Novena Época, t. XXIV, agosto de 2006, p. 1565.

Suprema Corte de Justicia de la Nación, (2014), Contradicción de Tesis 200/2013. Semanario Judicial de la Federación y su Gaceta, Décima Época, t. I, julio de 2014, página 46.

Suprema Corte de Justicia de la Nación, (2014), Tesis P./J. 43/2014, "Presunción de inocencia. Este principio es aplicable al procedimiento administrativo sancionador, con matices o modulaciones", Semanario Judicial de la Federación y su Gaceta, Décima Época, t. I, México, julio de 2014, página 46.

Suprema Corte de Justicia de la Nación, (2014), Versión taquigráfica de la sesión pública del 28 de enero de 2014, recuperado de https:// www.scjn.gob.mx/sites/default/files/versiones-taquigraficas/ documento/2016-11-07/28ene2014_0.pdf, consultado el 20 de enero de 2018.

Suprema Corte de Justicia de la Nación, (2015), Tesis: PC.I.A. J/52 A, "Suspensión en el juicio de amparo. Procede otorgarla contra la separación provisional de los elementos de instituciones de seguridad pública regidos por el artículo 123, apartado B, fracción 
XIII, de la Constitución Política de los Estados Unidos Mexicanos sujetos a un procedimiento administrativo de baja, para el efecto de que se continúen pagando los emolumentos que les corresponden", Semanario Judicial de la Federación y su Gaceta, Décima Época, t. III, octubre de 2015, p. 3115.

Tribunal Constitucional de España (1990), Sentencia número 138/1990 de 17 de septiembre de 1990, Boletín Oficial del Estado, núm. 254, 23 de octubre de 1990, recuperado de http://hj.tribunalconstitucional. es/es/Resolucion/Show/1563, consultado el 23 de febrero de 2018 Tribunal Constitucional de España (1989), Sentencia número 217/1989 de 21 de diciembre de 1989, Boletín Oficial del Estado, núm. 10, 11 de enero de 1990, recuperado de http:/hj.tribunalconstitucional.es/ gl/Resolucion/Show/1423\#complete_resolucion.

Tribunal Federal de Justicia Fiscal y Administrativa Sala Regional Centro II , (2013), Sentencia de 25 de octubre de 2013, Recurso de Inconformidad 1747/13-09-01-2, México.

Cómo citar este artículo: Sanabria, A. (2018). Presunción de inocencia en materia de procedimiento administrativo sancionador. Matices y modulaciones. Derecho Global. Estudios sobre Derecho y Justicia, 4 (10), pp. 51-76. 